W ILLI A M FA U L K N E R A N D THE TANGIBLE PA ST 


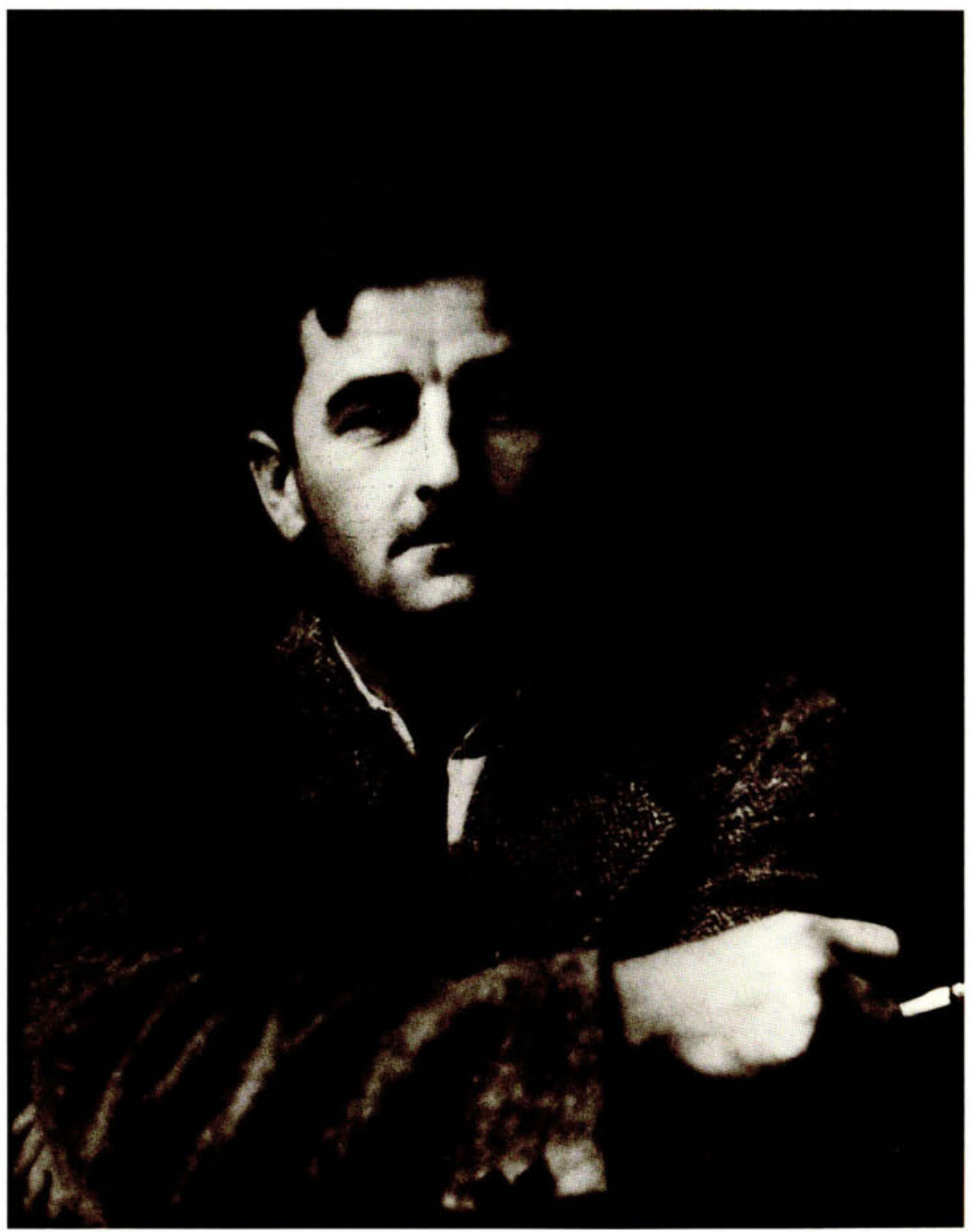




\section{William Faulkner}

and the

Tangible Past

THE ARCHITECTURE OF YOKNAPATAWPHA

Thomas S. Hines

University of California Press Berkeley Los Angeles London 
The publisher gratefully acknowledges the contribution provided by the Art Book Endowment

Fund of the Associates of the University of California Press, which is supported by a major gift

from the Ahmanson Foundation.

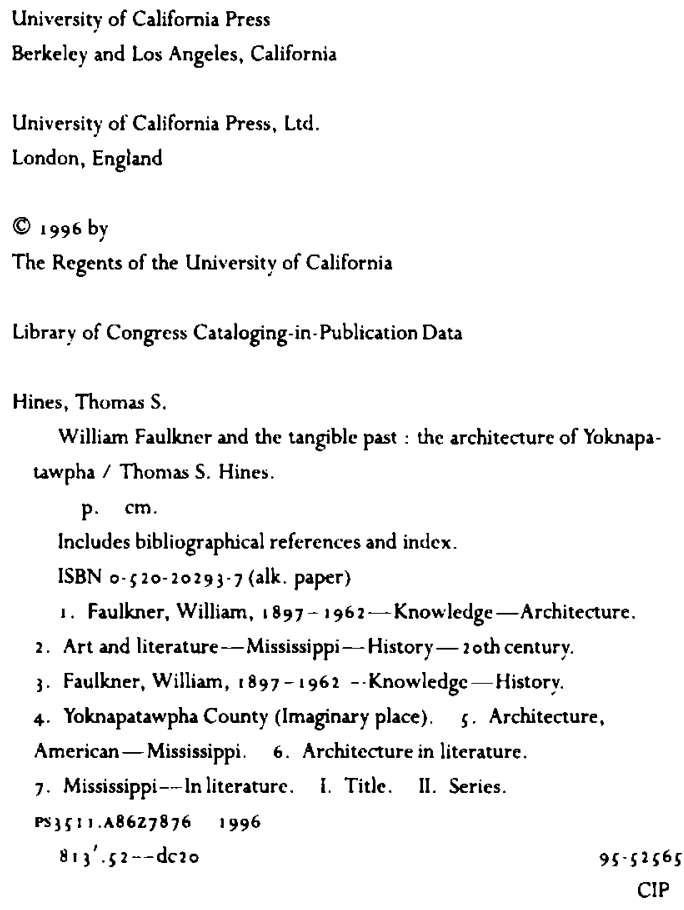

Printed in the United States of America

987654321

The paper used in this publication meets the minimum requirements of Arnerican National Standard for Information Sciences-Permanence of Paper for Printed Library Materials, ANSI Z 39.48-1984.

FR ON TIS PIECE

William Faulkner, photograph by J.R. Cofield (1931). 
This book is dedicated to my sunny California children, Taylor and Tracy, in the hope it will remind them that they are also children of

Yoknapatawpha. 